\title{
Insecticidal Activities of Four Native Entomopathogenic Fungus Beauveria bassiana Bals. (Vuill) Isolates Against Tribolium castaneum (Herbst, 1797) (Coleoptera: Tenebrionidae) Adults Under Laboratory Conditions
}

\author{
Seher Uçar ${ }^{1, a}$, Turgut Atay ${ }^{1, b, *}$, Yusuf Yanar ${ }^{1, c}$ \\ ${ }^{1}$ Department of Plant Protection, Faculty of Agriculture, Tokat Gaziosmanpaşa University, 60250 Tokat, Turkey \\ *Corresponding author

\begin{tabular}{|c|c|}
\hline A R T ICLE INFO & A B S T R A C T \\
\hline $\begin{array}{l}{ }^{\#} \text { This study was presented as an oral } \\
\text { presentation at the } 5 \text { th International } \\
\text { Anatolian Agriculture, Food, } \\
\text { Environment and Biology Congress } \\
\text { (Tokat, TARGID 2020) } \\
\text { Research Article }\end{array}$ & $\begin{array}{l}\text { In this work, control capacity of the four isolates (GN22-1, HP15, HP5-2, HP3-1) of } \\
\text { entomopathogenic fungus Beauveria bassiana Bals. (Vuill) were evaluated against Tribolium } \\
\text { castaneum (Herbst, 1797) (Coleoptera: Tenebrionidae) adults under laboratory conditions. To test the } \\
\text { effect of each of the isolate on adults of T. castaneum were dipped into } 1 \times 10^{8} \text { conidia/ml suspension } \\
\text { of each isolate. The data for mortality was recorded after } 3^{\text {rd }}, 5^{\text {th }}, 7^{\text {th }}, 9^{\text {th }}, 11^{\text {th }}, 13^{\text {th }}, 15^{\text {th }}, 17^{\text {th }}, 19^{\text {th }} \text {, } \\
21^{\text {st }} \text {, and } 23^{\text {rd }} \text { day. Thirteen days after application, isolates were listed as GN22-1 }(72.85 \%), \text { HP3-1 } \\
(48.88 \%) \text {, HP15 ( } 47.37 \%) \text { and HP5-2 }(30.43 \%) \text { based on the mortality rate they caused. Mortality } \\
\text { rate was } 83.52 \% \text { at the end of the } 23^{\text {rd }} \text { day with isolate GN22-1. While HP3-1 }(53.74 \%) \text { and HP15 } \\
(52.24 \%) \text { caused more than } 50 \% \text { effect at the end of } 23 \text { days incubation period, the effect of HP5-2 } \\
\text { remained only } 32.51 \% \text {. In addition, LT } \mathrm{T}_{50} \text { and LT } 90 \text { rates were also determined. We arrive to the } \\
\text { conclusion that especially GN22-1 isolate can has a potential in the control of this insect and may } \\
\text { serve an alternative to chemical insecticides. }\end{array}$ \\
\hline
\end{tabular} \\ Effects \\ Tribolium castaneum \\ Lethal time \\ seheruucar.60@gmail.com (iD) https://orcid.org/0000-0002-2648-0167 \\ c@yusuf.yanar@gop.edu.tr $\quad$ (iD) https://orcid.org/0000-0002-5795-6340 \\ b@turgut.atay@gop.edu.tr (iD) https://orcid.org/0000-0002-9074-0816
}

\section{Introduction}

Insect pest infestation can cause up to $40 \%$ loss in stored products worldwide. Red flour beetle, Tribolium castaneum (Herbst, 1797) (Coleoptera: Tenebrionidae) is a widespread and most destructive pest of stored products throughout the world. Both adults and larvae feed in a variety of materials containing flour, cereals, pasta, biscuits, beans, and nuts. Besides the product losses caused by feeding, this insect imparts a nauseous smell and taste to the infested material decreasing its nutritive value (Karunakaran et al., 2004). Attempts to control of stored products pests relies on physical control and mostly fumigants, such as methyl bromide or phosphine. Research has shown that synthetic insecticides are extremely toxic to non-target species and have harmful environmental impacts. Also, harmful insects have developed resistance to many pesticides. Hence, alternatives and more safer control methods should be developed (Upadhyay and Ahmad, 2011). Biological control efforts are the most important issue for achieve this goal. This method involves the use of natural enemies such as parasites, predators, and pathogens.

Entomopathogenic fungi (EPF) are widespread in terrestrial ecosystems and play an important role in the regulation of insect populations. There are about 90 genera and 700 species with entomopathogenicity (Roberts and Humber, 1981). Insect fungal pathogens have a wide variety of hosts, can be mass-produced simply, rabidly, economically, and can be used with the same technological means as traditional contact insecticides. In this context, Beauveria bassiana (Balsamo) Vuillemin and Metarhizium anisopliae (Metschn.) Sorokin 1883 are the most studied fungal species for the control of stored-product insect species (Rumbos and Athanassiou, 2017). The anamorphic entomopathogenic fungus $B$. bassiana is natural enemies of a wide range of insects and arachnids and has a cosmopolitan distribution. This fungus has been documented to occur naturally in more than 700 species of insect hosts (Imoulan et al., 2017). 
Beauveria bassiana has been tested against most of the major stored-product insect species (mostly coleopteran pest and only a few species lepidopteran pest), under various types of conditions and product in the world (Rumbos and Athanassiou, 2017). Some studies were performed to assess the ability of $B$. bassiana as a bioinsecticide for various stored product pests in Turkey. Most of these studies have mostly focused on coleopteran pests (Sevim et al., 2015; Er et al., 2016; Atay et al., 2017; Ak, 2019; Özdemir et al., 2020). This study was conducted to assess the efficacy of four entomopathogenic fungus Beauveria bassiana Bals. (Vuill) isolates (GN22-1, HP15, HP5-2, HP3-1) of $1 \times 10^{8}$ conidia/ml concentrations against Tribolium castaneum adults under laboratory conditions.

\section{Material and Methods}

\section{Insect Culture}

Insects from a stock culture of Tribolium castaneum (Tokat Gaziosmanpasa University, Faculty of Agriculture, Department of Plant Protection in Tokat, Turkey) were obtained that reared in the laboratory on broken wheat at $28 \pm 2{ }^{\circ} \mathrm{C}$ and $65-75 \%$ R.H.

\section{Fungal Isolates}

For current study, 4 isolates of B. bassiana (GN22-1, HP15, HP5-2, HP3-1) were chosen from the fungal culture collection of the Mycology Laboratory at the Tokat Gaziosmanpasa University, Faculty of Agriculture, Department of Plant Protection in Tokat, Turkey. These isolates were originally isolated from naturally infected Hypera postica (Gyllenhal 1813) (Coleoptera, Curculionidae) and Gonioctena fornicata (Brüggemann 1873) (Coleoptera, Chrysomelidae) adults collected from alfalfa fields in Tokat Province, Turkey.

\section{Inoculum Preparation from Entomopathogenic} Fungal Isolates

Fungal isolates were cultured on Potato Dextrose Agar (PDA) in Petri dishes and incubated at $25 \pm 2{ }^{\circ} \mathrm{C}$ with a $16 / 8$ (L/D) photoperiod. Spores were harvested from 17 day-old cultures with $10 \mathrm{ml}$ of sterilized water containing $0.02 \%$ Tween 80 . The conidial suspensions were filtered through 3 sheets of sterile cheesecloth to eliminate particles and then spore suspension from each isolate was adjusted to $1 \times 10^{8}$ (Saruhan et al., 2017).

\section{Application of Fungal Inoculum}

Tribolium castaneum adults were dipped into $1 \times 10^{8}$ conidia/ml suspension of each isolate for 7-8 sec. and placed in Petri dishes containing broken wheat as a food. The experiment was laid out in completely randomized design with 9 replications and 10 adults were used for each replication. In control, adults were treated with $0,02 \%$ aqueous solution of Tween $80(\mathrm{v} / \mathrm{v})$. The treated adults were maintained at $25 \pm 2^{\circ} \mathrm{C}$ with a $16 / 8$ (L/D) photoperiod. The mortality was recorded up to 23 day of treatment with an interval of two days. Dead insects were separated from the Petri dishes and taken to another Petri dishes with a moist filter paper and mycelium development was observed.

\section{Statistical Analysis}

The raw data was first converted to $\%$ mortality values and then exposed to Arcsine transformation. All the data were analysed using analysis of variance (ANOVA) and the means were compared with Tukey's multiple comparison test at 5\% significant level. All statistical analyses were carried out by using the MINITAB Release 16 packet program. $\mathrm{LT}_{50}$ and $\mathrm{LT}_{90}$ values were calculated by using the Probit analysis.

\section{Results and Discussion}

The four Beauveria bassiana fungal isolates were tested against Tribolium castaneum adults at a concentration of $1 \times 10^{8}$ conidia $/ \mathrm{ml}$. Mortality of $T$. castaneum in all isolates was significantly different from each other. Table 1 shows that the entomopathogenic fungal isolates produced different insecticidal activity rates after 3 days post inoculation. Long exposure interval had a positive effect on the mortality rate of $T$. castaneum. Among the entomopathogenic fungal isolates, GN22-1 (51.07\%) showed the highest insecticidal activity against $T$. castaneum at the end of day 9 , followed by HP3-1 (44.37\%), HP15 (40.67\%), and HP5-2 (23.68 \%). Thirteen days after the application, isolates were listed as GN22-1 (72.85\%), HP3-1 (48.88\%), HP15 (47.37\%), and HP5-2 (30.43\%) according to the mortality rates they caused. Mortality rate of isolate GN22-1 was $83.52 \%$ at the end of the $23^{\text {rd }}$ day. While HP3-1 (53.74\%) and HP15 $(52.24 \%)$ caused more than $50 \%$ effect at the end of 23 days incubation period, the effect of HP5-2 remained only $32.51 \%$ (Table 1).

Table 1. Mortality of Tribolium castaneum adults exposed to Turkish isolates of the entomopathogen Beauveria bassiana

\begin{tabular}{|c|c|c|c|c|c|}
\hline \multirow{2}{*}{ Days/Isolates } & \multicolumn{5}{|c|}{ Mortality $\pm \operatorname{SEM}^{*}(\%)$} \\
\hline & HP5-2 & HP3-1 & GN22-1 & HP-15 & Control \\
\hline 3 & $2.03 \pm 1.01^{\mathrm{bc} * *}$ & $13.01 \pm 0.18^{\mathrm{a}}$ & $6.91 \pm 0.87^{\mathrm{ab}}$ & $12.73 \pm 0.82^{\mathrm{a}}$ & $0.00 \pm 0.00^{\mathrm{c}}$ \\
\hline 5 & $5.93 \pm 1.31^{\mathrm{b}}$ & $26.05 \pm 0.49^{\mathrm{a}}$ & $21.86 \pm 0.25^{\mathrm{a}}$ & $23.93 \pm 0.39^{\mathrm{a}}$ & $0.00 \pm 0.00^{\mathrm{c}}$ \\
\hline 7 & $14.20 \pm 1.75^{\mathrm{b}}$ & $35.31 \pm 0.31^{\mathrm{a}}$ & $38.76 \pm 0.23^{\mathrm{a}}$ & $31.78 \pm 0.49^{\mathrm{a}}$ & $0.00 \pm 0.00^{\mathrm{c}}$ \\
\hline 9 & $23.68 \pm 0.55^{b}$ & $44.37 \pm 0.28^{\mathrm{a}}$ & $51.07 \pm 0.40^{\mathrm{a}}$ & $40.67 \pm 0.83^{\mathrm{a}}$ & $0.00 \pm 0.00^{\mathrm{c}}$ \\
\hline 11 & $28.30 \pm 0.52^{\mathrm{c}}$ & $48.88 \pm 0.50^{\mathrm{ab}}$ & $63.62 \pm 0.40^{\mathrm{a}}$ & $43.98 \pm 0.99^{b}$ & $0.00 \pm 0.00^{\mathrm{d}}$ \\
\hline 13 & $30.43 \pm 0.63^{c}$ & $48.88 \pm 0.50^{\mathrm{b}}$ & $72.85 \pm 0.56^{\mathrm{a}}$ & $47.37 \pm 1.24^{\mathrm{b}}$ & $0.00 \pm 0.00^{\mathrm{d}}$ \\
\hline 15 & $30.43 \pm 0.63^{b}$ & $50.05 \pm 0.65^{b}$ & $78.37 \pm 1.69^{a}$ & $47.37 \pm 1.24^{\mathrm{b}}$ & $0.00 \pm 0.00^{\mathrm{c}}$ \\
\hline 17 & $31.46 \pm 0.76^{\mathrm{b}}$ & $50.05 \pm 0.65^{\mathrm{b}}$ & $81.69 \pm 1.66^{\mathrm{a}}$ & $47.37 \pm 1.24^{\mathrm{b}}$ & $0.51 \pm 0.71^{\mathrm{c}}$ \\
\hline 19 & $32.51 \pm 0.97^{\mathrm{b}}$ & $51.34 \pm 0.91^{\mathrm{b}}$ & $81.70 \pm 1.66^{\mathrm{a}}$ & $47.38 \pm 1.24^{\mathrm{b}}$ & $2.03 \pm 1.01^{\mathrm{c}}$ \\
\hline 21 & $32.51 \pm 0.97^{\mathrm{b}}$ & $51.34 \pm 0.91^{\mathrm{b}}$ & $82.68 \pm 1.57^{\mathrm{a}}$ & $48.50 \pm 1.21^{\mathrm{b}}$ & $3.16 \pm 1.01^{\mathrm{c}}$ \\
\hline 23 & $32.51 \pm 0.97^{\mathrm{b}}$ & $53.74 \pm 1.08^{\mathrm{b}}$ & $83.52 \pm 1.30^{\mathrm{a}}$ & $52.24 \pm 0.81^{\mathrm{b}}$ & $4.53 \pm 0.91^{\mathrm{c}}$ \\
\hline
\end{tabular}


Table 2. Lethal time $\left(\mathrm{LT}_{50}\right.$ and $\left.\mathrm{LT}_{90}\right)$ values (days) of Tribolium castaneum adults treated with isolates of the entomopathogenic fungus Beauveria bassiana

\begin{tabular}{l|cccc}
\hline \multicolumn{1}{c|}{ Isolates } & Slope \pm SE & LT $_{50}(95 \%$ fiducial limit $)$ & LT $_{90}(95 \%$ fiducial limit $)$ & chi-square \\
\hline HP5-2 & $0.044 \pm 0.007$ & $28.813(24.749-36.426)$ & $58,043(47.053-79.505)$ & 78.735 \\
HP3-1 & $0.043 \pm 0.007$ & $17.186(15.236-19.928)$ & $46.844(38.909-61.436)$ & 74.579 \\
GN22-1 & $0.103 \pm 0.007$ & $10.327(9.331-11.229)$ & $22.808(21,219-24.875)$ & 10.29 \\
HP15 & $0.043 \pm 0.007$ & $18,615(16.437-21.966)$ & $48,581(39.975-64.900)$ & 99.394 \\
\hline
\end{tabular}

When the $\mathrm{LT}_{50}$ values of the isolates applied in the study were analysed, the most effective isolate was GN221 (10.327 days) and this followed by HP3-1 (17.186), HP15 (18.615) and HP5-2 (28.813), respectively. $\mathrm{LT}_{90}$ rates were ranged like those of the $\mathrm{LT}_{50}$ (Table 2).

Main effects of different EPF isolates and exposure intervals on percent mortality of $T$. castaneum were highly significant. The isolates used in this study did not cause mortality more than $39 \%$ on the $7^{\text {th }}$ day. Akmal et al. (2020) observed a low effect $(32.5 \%)$ against $T$. castaneum adults $7^{\text {th }}$ day after the application with $5 \times 10^{8} \quad$ spores $/ \mathrm{ml}$ concentration of B. bassiana. GN22-1 has started to show a significant effect from the $13^{\text {th }}$ day and this effect increased to over $80 \%$ on the $17^{\text {th }}$ day. The effect of all other isolates did not exceed $55 \%$ at the end of the $23^{\text {rd }}$ day. Similarly, Moore et al. (2000) stated that the virulence of fungal strains differed significantly against stored grain insect pests. Padin et al. (2002) reported that B. bassiana had no significant insecticidal effect on $T$. castaneum by exposing pest-infested wheat and bean seeds to conidia of B. bassiana. Rice and Cogburn (1999), recorded an efficiency more than $80 \% \mathrm{~B}$. bassiana isolate against $T$. castaneum adult at 21 days after treatment. Similarity, in this study we revealed $82 \%$ mortality with isolates GN221 at the end of 21 days. On the other hand, Rizwan et al. (2019) reported that B. bassiana-treated wheat gave mortality rate with $31.67 \%$ against $T$. castaneum at the highest concentration $\left(1 \times 10^{8}\right.$ conidia $\mathrm{kg}^{-1}$ of wheat $)$ after 21-day exposure time. Also, that study, revealed an additive effect of $B$. bassiana, when used with diatomaceous earth against adults of this pest. In our study all isolates used showed that more than effect $32.5 \%$ effect at the end of 21 days. This differences between two studies might be related to the variation in virulence of the isolates tested in both studies.

We arrive to the conclusion that especially GN22-1 isolate can has a potential in the control of this insect and may serve an alternative to chemical insecticides.

\section{References}

Ak K. 2019. Efficacy of entomopathogenic fungi against the stored-grain pests, Sitophilus granarius L. and S. oryzae L. (Coleoptera: Curculionidae). Egypt J Biol Pest Control, 29 (12): 1-7. DOI: https://doi.org/10.1186/s41938-019-0115-y

Akmal M, Freed S, Bilal M, Malik MN. 2020. A laboratory evaluation for the potential of entomopathogenic fungi against Tribolium castaneum (Herbst.) (Coleoptera: Tenebrionidae). TURJAF, 8 (6): 1232-1235. DOI: https://doi.org/10.24925/turjaf.v8i6.1232-1235.1460

Atay T, Yanar D, Ertürk S, Yanar Y. 2017. Efficacy of entomopathogenic fungus Beauveria bassiana Bals. (Vuill) against Granary Weevil [Stophilus granarius (L.) (Coleoptera: Curculionidae)] under laboratory conditions. 6th Entomopathogens and Microbial Control Congress, Tokat 14-16 Eylül, p72.
Er MK, Tunaz H, Ücük C, Barış C, Işıkber AA. 2016. Occurrence of entomopathogenic fungi on insect pests of stored wheat and maize in Central and South Anatolia in Turkey. Türk. entomol. derg., 40(3): 249-263. DOI: http://dx.doi.org/ 10.16970/ted.56436

Imoulan A, Hussain M, Kirk PM, El Meziane A, Yao YJ. 2017. Entomopathogenic fungus Beauveria: Host specificity, ecology and significance of morpho-molecular characterization in accurate taxonomic classification. J. Asia Pac. Entomol., 20(4): 1204-1212. DOI: https://doi.org/ 10.1016/j.aspen.2017.08.015

Karunakaran C, Jayas DS, White NDG. 2004. Identification of wheat kernels damaged by the red flour beetle using X-ray image. Biosyst. Eng., 87(3): 267-274. DOI: https://doi.org/ 10.1016/j.biosystemseng.2003.12.002

Moore D, Lord JC, Smith SM. 2000. Pathogens (Eds. Bh. Subramanyam \& D.W. Hagstrum), In: Alternatives to Pesticides in Stored-Product IPM. Kluwer Academic Publishers, 193-227 pp. ISBN 978-1-4615-4353-4

Özdemir İO, Tuncer C, Erper İ, Kushiyev R. 2020. Efficacy of the entomopathogenic fungi; Beauveria bassiana and Metarhizium anisopliae against the cowpea weevil, Callosobruchus maculatus F. (Coleoptera: Chrysomelidae: Bruchinae). Egypt J Biol Pest Control, 30 (24): 1-5. DOI: https://doi.org/10.1186/s41938-020-00219-y

Padin SB, Dal Bello GM, Fabrizio M. 2002. Grain losses caused by Tribolium castaneum, Sitophilus oryzae and Acanthoscelides obtectus in stored durum wheat and beans treated with Beauveria bassiana. J. Stored Prod. Res., 38: 69-74. DOI: https://doi.org/10.1016/S0022-474X(00)00046-1

Roberts DW, Humber RA. 1981. Entomogenous Fungi, (Editors: G. T. Cole \& B. Kendrick), Biology of Conidial Fungi, Academic Press, New York, 201-236 pp. ISBN 9780323138994

Rice WC, Cogburn RR. 1999. Activity of the entomopathogenic fungus Beauveria bassiana (Deuteromycota: Hyphomycetes) against three Coleopteran pests of stored grain. J. Econ. Entomol., 92: 691- 694. DOI: https://doi.org/10.1093/ jee/92.3.691

Rizwan M, Atta B, Rizwan M, Sabir AM, Shah ZU, Hussain M. 2019. Effect of the entomopathogenic fungus, Beauveria bassiana, combined with diatomaceous earth on the red flour beetle, Tribolium castaneum (Herbst) (Tenebrionidae: Coleoptera). Egypt J Biol Pest Control., 29 (27): 1-6. DOI: https://doi.org/10.1186/s41938-019-0131-y

Rumbos CI, Athanassiou CG. 2017. Use of entomopathogenic fungi for the control of stored-product insects: can fungi protect durable commodities? J Pest Sci, 90:839-854. doi: 10.1007/s10340-017-0849-9

Saruhan İ, Toksöz S, Erper İ. 2017. Evaluation of some entomopathogenic fungi against the fall webworm (Hyphantria cunea Durry, Lepidoptera: Arctidae). Selcuk J Agr Food Sci, 31(2): 76-81. doi: 10.15316/SJAFS.2017.22

Sevim A, Sevim E, Demirci M. 2015. Virulence of entomopathogenic fungi and bacteria against stored product pests. CBU J. of Sci. 11(2): 79-87. DOI: https://doi.org/ 10.18466/cbujos.71031

Upadhyay RK, Ahmad S. 2011. Management strategies for control of Stored grain insect pests in farmer stores and public ware houses. World J. Agric. Res., 7 (5): 527-549. 